\title{
A case of subacute sclerosing panencephalitis (SSPE)
}

\author{
G N Lucas ${ }^{1}$, M A L Faiz ${ }^{2}$ \\ Sri Lanka Journal of Child Health, 2000; 29:122-3
}

(Key words: subacute sclerosing panencephalitis, SSPE)

\section{Introduction}

SSPE is a slowly progressive, fatal form of encephalitis affecting children and young adults. It was first clearly described and a viral aetiology postulated by Dawson ${ }^{1}$. In 1967 elevated antibody titres to measles virus in serum and CSF were reported and viral antigen demonstrated in brain tissue by immunofluorescence ${ }^{2}$. The first successful recovery of measles from brain tissue occurred in $1969^{3}$.

The clinical course of SSPE has been divided into 4 stages $^{4}$.

Stage 1 is insidious and first noticed by declining school performance or behavioural changes. Impaired memory, declining intellectual skills and rapid mood swings characterize this stage. This stage may last for several months.

In stage 2 definite neurological involvement is evident. Myoclonic jerks, motor disability and convulsive seizures are common. Ocular signs, including optic atrophy, are seen in $50 \%$ of patients.

After several weeks or months, stage 3 manifests with decerebrate rigidity, decorticate posturing and coma.

In stage 4 most cortical functions are lost. Pathologic laughter and crying, random eye movements and flexure posturing occur.

There is only a solitary report of a case of SSPE from Sri Lanka, a case with a long survival of 8 years ${ }^{5}$.

${ }^{1}$ Consultant Paediatrician, ${ }^{2}$ Paediatric Registrar, Lady Ridgeway Hospital, Colombo.

\section{Case report}

A nine years and eight month old school-girl from Katunayaka was admitted to the Lady Ridgeway Hospital in February, 2000 with a history of deterioration of hand writing of 8 months duration and recurrent short lasting jerky movements of limbs (myoclonic jerks) of 2 months duration. There was no loss of consciousness and no fever.

The child developed generalised afebrile tonic-clonic seizures at the age of 7 years and was started on carbamazepine and sodium valproate therapy. There was no family history of epilepsy and no consanguinity.

At the age of eight and a half months the child had a febrile illness with cold and cough. On the third day of the illness she developed a maculo-papular rash which lasted for 5 days. A clinical diagnosis of measles was made and because of this the measles vaccine which was due at 9 months of age was not given.

On examination, the child was fully conscious but emotional. There was a loss of immediate and long term memory. The speech was not clear. The cranial nerves, including the fundus, were normal. The power was grade 3 on the right side and grade 4 on the left side. The tone was variable in the 4 limbs ranging from spastic to normal. The upper limb reflexes were normal but the knee jerks and ankle jerks were exaggerated. The plantars were extensor. The sensation was normal.

The EEG showed regular paroxysms of slow and sharp waves with spikes at high voltage occurring symmetrically (Figure 1). 


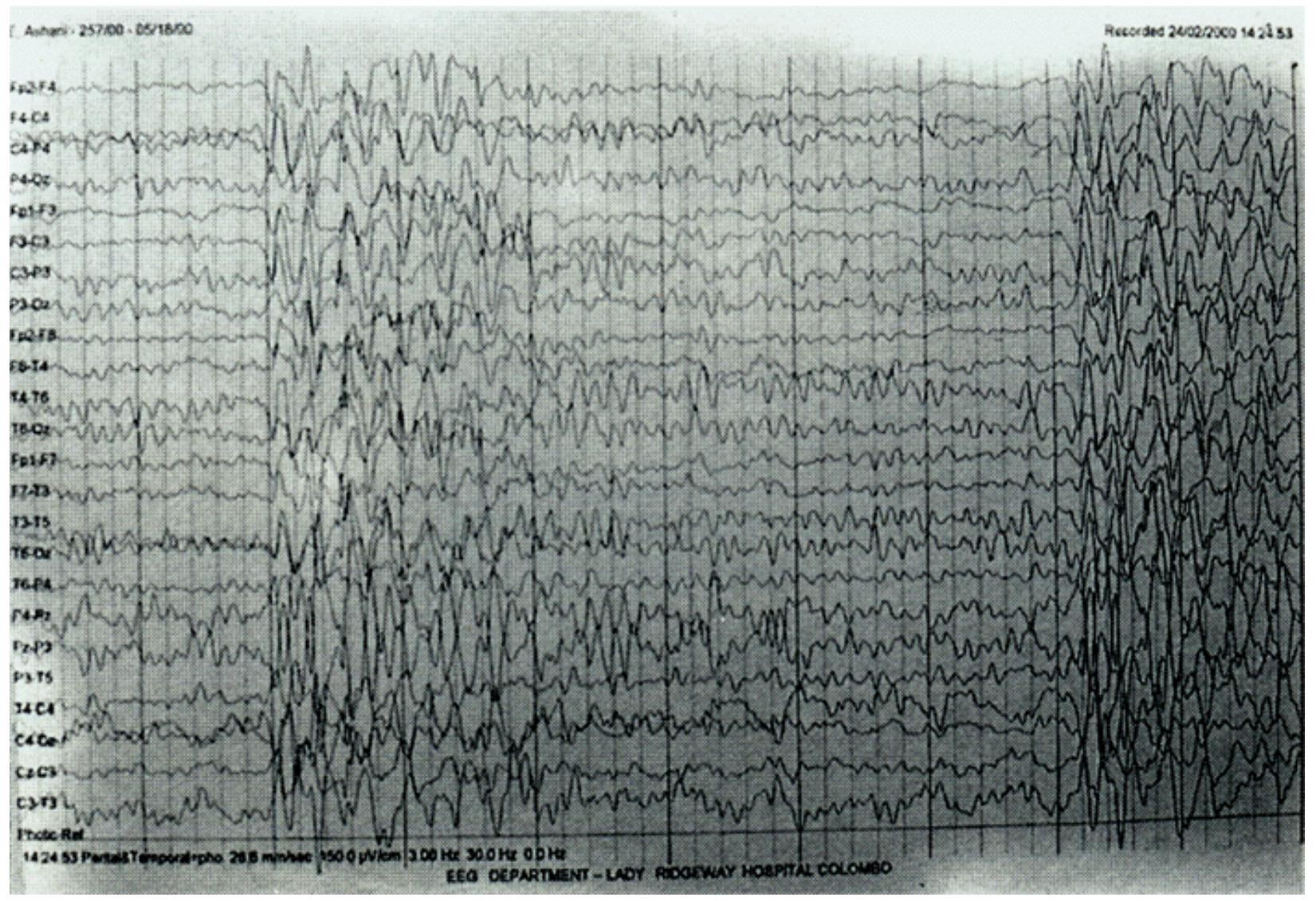

Figure 1 EEG showing paroxysms of slow and sharp waves with spikes at high voltage

The ELISA test was used for diagnosis. Measles specific IgM antibody was negative in blood indicating absence of a recent attack of measles. However measles specific IgG antibody was positive in the CSF thus confirming the diagnosis of SSPE.

\section{References}

1. Dawson J R. Cellular inclusions in cerebral lesions of lethargic encephalitis. American Journal of Pathology 1933; 9:7-15.

2. Connolly J H, Allen I V, Hurwitz L J, Miller J H D. Measles virus antibody and antigen in subacute sclerosing panencephaltis. Lancet 1967; 1: $542-4$.
3. Chen T T, Watanabe 1, Zeman W, Mealey J. Subacute sclerosing panencephalitis: propagation of measles virus from brain biopsy in tissue culture. Science 1969; 163:1193-4.

4. Jabour J T, Garcia J G, Lemmi H, Ragland J, Duenas D A, Sever J L. Subacute sclerosing panencephalitis. A multidisciplinary study of eight cases. Journal of American Medical Association 1969; 207:2248-54.

5. De Silva D G H, Jayantha U K. Long term survival in subacute sclerosing panencephalitis. Ceylon Medical Journal 1992; 37:52. 